УДК $811.111 ’ 367.335 ’ 255.2: 339$

\title{
Э.Р. Михайлова
}

\section{О НЕКОТОРЫХ ОСОБЕННОСТЯХ ПЕРЕВОДА СЛОЖНЫХ ПРЕДЛОЖЕНИЙ (НА МАТЕРИАЛЕ ДЕЛОВОЙ КОММЕРЧЕСКОЙ КОРРЕСПОНДЕНЦИИ НА АНГЛИЙСКОМ И РУССКОМ ЯЗЫКАХ)}

В статье рассматриваются некоторые особенности перевода с английского языка на русский оформленных сложными предложениями высказываний, которые употребляются в деловой коммерческой корреспонденции. При переводе необходимо учитывать все разнообразие содержащейся в них информации, характерной для делового письма, а также прагматические и стилистические особенности сложных предложений. Для достижения адекватного перевода в ряде случаев используют различные переводческие трансформации, такие как: перестановки, замены, добавления, опущения. В некоторых случаях возможна потеря и изменение информации этического характера, но с обязательным сохранением передаваемой когнитивно-оценочной и важной прагматической информации, общей коммуникативно-информационной структуры высказывания. При условии соблюдения общих стилистических норм исходного и переводящего языков, характерных для письменного делового общения, между ними наблюдаются различия, проявляющиеся в большей лаконичности, категоричности, реалистичности и настойчивости русскоязычных высказываний. Произведенные преобразования позволяют выявить «эмоционально-психологические нюансы», которые придают большее значение оценке ситуации и подчеркивают понимание адресантом (одним из партнеров) значимости того или иного факта.

Ключевые слова: сложные предложения, сложноподчиненные и сложносочиненные предложения, переводческие трансформации, эквивалентный перевод, адекватный перевод, уровни эквивалентности, коммуникативноинформационная структура высказывания.

DOI: $10.35634 / 2412-9534-2021-31-2-264-270$

Одной из трудностей перевода деловой коммерческой корреспонденции является перевод высказываний, представленных сложными предложениями, которые употребляются во всех ее жанрах. Для деловой коммерческой корреспонденции характерно содержание когнитивной, оценочной, эмотивно-экспрессивной и в определенной степени эстетической информации. В целях анализа языкового материала эстетическая информация рассматривается как корректное употребление соответствующих языковых средств исходного и переводящего языков согласно языковым и этическим нормам делового общения для должной передачи нужной информации в целях достижения ее адекватного восприятия адресатом (партнером).

При переводе деловой коммерческой корреспонденции необходимо также учитывать ее стилистические и прагматические особенности.

В качестве стилистических особенностей делового письма отмечают краткость, информативность, убедительность, доказательность, достигаемых благодаря использованию характерного для официального письма синтаксиса, который отличает «логизированный строй» предложений, призванный отражать логическую последовательность элементов содержания и соответствовать традиционным для данного языка нормам словорасположения [2].

В качестве прагматических особенностей, сложных предложений-высказываний, следует отметить использование определенных эмфатических конструкций, инверсии, наклонения, видовременных форм сказуемых в частях сложного предложения, модальные лексико-грамматические языковые средства, коммуникативно-информационную структуру всего высказывания, обусловленную «логизированным строем» предложений; союзов и союзных слов, формирующих логический контекст; участие самих сложных предложений в составе прямых и косвенных речевых актов, в значительной степени определяющих, в конечном итоге, иллокутивную силу, результирующий смысл высказываний и сообщаемые им импликатуры, как правило, конвенциональные для ясности сообщаемого и быстрого его понимания адресатом в целях своевременного решения поставленных стратегических и тактических задач делового общения [6].

Для достижения адекватного перевода, который определяется как перевод, удовлетворяющий требованиям эквивалентности на том или ином ее уровне (на уровне цели коммуникации, указания на ситуацию, способа описания ситуации, синтаксических структур и на уровне языковых знаков) и, в 
первую очередь, поставленной прагматической задаче [4; 5], в ряде случаев возникает необходимость использовать различные переводческие трансформации, такие как: перестановки (изменение порядка слов в предложении, порядка следования компонентов сложного предложения), замены (замены форм слова, частей речи, членов предложения, синтаксические, лексические замены антонимический перевод, компенсации), добавления, опущения, описанные Л.С. Бархударовым [1]. При переводе других сложных предложений, употребляемых в деловом письме, (равно как и предложений, употребляемых в текстах из других профессиональных сфер [3], практически не происходит существенных изменений в их семантико-синтаксической структуре.

Ниже рассмотрим некоторые случаи перевода сложных предложений с английского языка на русский.

1. Перевод без изменения синтаксической конструкции имеет место в сложноподчиненных предложениях с придаточным определительным идентифицирующим, функция которого заключается в идентификации референта, обозначаемого именной группой, включающей придаточное определительное. В английском языке в отличие от русского придаточное определительное в идентифицирующей функции в нейтральном высказывании на письме не отделяется пунктуационно, в частности, запятой.

The cases in which the equipment is packed are to be marked on three sides - on two opposite sides and on the top of the case. - Ящики, в которых упаковано оборудование, маркируются с трех сторон на двух противоположных боковых сторонах и сверху ящика [8].

В русском придаточном определительном изменен порядок слов согласно законам русской письменной речи, где информационная роль порядка слов возрастает к концу предложения. В русскоязычном предложении, для которого характерен принцип «линейной» подачи информации, сначала вводится вспомогательная информация, а затем - основная, располагающаяся после сказуемого [2]. В переведенном высказывании подлежащее в придаточном идентифицирующем стоит после сказуемого и является в нем ремой, на него падает логическое ударение, что совершенно естественно для нейтрального высказывания на русском языке. Анафорическое относительное местоимение и сказуемое, представляющие вместе с подлежащим тематический компонент, занимают начальную позицию в придаточном определительном.

В придаточном исходного языка в силу грамматикализованности порядка слов в английском предложении подлежащее стоит на первом месте перед сказуемым. При логическом ударении на подлежащем компоненты коммуникативно-информационной структуры придаточного определительного в английском и русском языках совпадают, различаясь в порядке их следования.

2. При переводе на русский язык сложных предложений-высказываний весьма часто опускаются лексико-грамматические смысловые компоненты, представляющие прагматическую пресуппозицию, информация которой известна из контекста и является избыточной в переводящем языке [6]. Так, придаточное определительное идентифицирующее, переводится причастием в функции определения, что ведет к компрессии информации и делает фразу более лаконичной. При этом могут иметь место и другие лексико-грамматические преобразования. Коммуникативно-информационная структура высказываний исходного и переводящего языков в целом сохраняется.

The packages for which special handling is required shall have additional marking... - Mecma, требующие специального обращения, должны иметь дополнительную маркировку... [8].

Трансформации, произведенные при переводе на русский язык английского высказывания: замена придаточного определительного причастным оборотом в соответствующей функции, связанное с этим опущение анафорического относительного местоимения в тематической функции, замена пассивной сказуемостной группы в исходном придаточном причастием активного залога, изменение направленности действия: в русском предложении оно направлено непосредственно от конкретизированного агенса-подлежащего Места на объект специального обращения - прямое дополнение - сообщают высказыванию смысловой оттенок «настоятельности, динамичности», изменяя в определенной степени модальность исходного высказывания, звучащего вследствие употребления пассивной конструкции несколько отстраненно.

3. В сложноподчиненном предложении с придаточным определительным дескриптивным, отделяющимся от главного запятой, главное и придаточное могут переводиться отдельными предложениями для снятия двусмысленности. 
The equipment will be available at reasonable prices and allowance is made for depreciation. The prices do not include import duties, which should be paid by the Buyer in compliance with the customs relations in force in your country. -

Оборудование будет реализовываться по разумным ценам с учетом его амортизации. Цены не включают импортные пошлины. Они должны быть уплачены покупателем оборудования в соответствии с таможенными правилами, существующими в Вашей стране.

Парцелляция придаточного предложения в переводе на русский язык четко обозначает референт, соотносимый с именной группой импортные пошлины, и допускает лишь одно ее прочтение. Сравните перевод без парцелляции придаточного дескриптивного: Цены не включают импортные пошлины, которые должны быть уплачены покупателем оборудования в соответствии с таможенными правилами, существующими в Вашей стране.

Придаточное определительное в русском языке может быть понято и как придаточное идентифицирующее, что предполагает также возможность другого референта. И адресат (читающий), не вполне знакомый со всеми тонкостями реальной ситуации, может быть несколько озадачен или введен в заблуждение.

4. Замена английского придаточного предложения при переводе на русский одним словом, обобщающим содержание придаточного, также придает лаконичность высказыванию. При этом могут иметь место большие или меньшие изменения в семантико-синтаксической структуре сложноподчиненного предложения при неизменности общей коммуникативно-информационной структуры высказывания.

The penalties will be deduced from the Sellers' invoices when they will be paid by the Buyers. Штраф будет удерживаться со счетов Продавца при оплате их Покупателем [8].

Замена подлежащно-сказуемостной группы в английском придаточном времени существительным в русском переводе ведет не только к лаконичности высказывания, но и к некоторому изменению его модальности. Высказывание становится более категоричным, обязательным и реалистичным. Этому способствует и употребление в переводе существительного «The penalties - umpaф» и сказуемого «будет удержсиваться» в форме единственного числа, что подчеркивает целостность того множества, которое обозначается этими языковыми средствами. Сравните: Штрафы будут удерживаться со счетов Продавца, когда их будет оплачивать Покупатель. Коммуникативно-информационная структура исходного высказывания в целом сохранена.

При переводе на русский язык замене английской словесной конструкции одним словом может подвергнуться придаточное в препозиции.

Should the shipment of the equipment not be notified or be notified with delay, the Sellers are to pay to the Buyers penalty at the rate of $0,1 \%$ of the value of the equipment already shipped. - За неизвешение или несвоевременное извещение о произведенной отгрузке оборудования Продавеи уплачиваem Покупателю шттраф в размере 1\% от стоимости отгруженного оборудования [8].

Использование в английском придаточном предложении сослагательного наклонения для выражения маловероятного условия, возможного в будущем, благодаря употреблению синкретичного вспомогательного глагола should, сохраняющего в то же время и значение модального глагола, сообщает высказыванию модальность «предполагаемой вероятности»- «Случись, что не будет...». Благодаря частичной инверсии - вынесению вспомогательного глагола should в начало высказывания, последнее приобретает большую экспрессивность. В нем выражается более тесная связь между компонентами сложноподчиненного предложения, между предполагаемым условием и его следствием, т.е. между возможным нежелательным нарушением одного из условий контракта и последующим за это незамедлительным наказанием. Сравните с нейтральным If the shipment of the equipment should not be notified or be notified with delay, the Sellers...-Eсли не будет извещения или своевременного извещения об отгрузке оборудования, Продавеи... .

Главное предложение представляет собой «гибридный речевой акт» благодаря своему содержанию и употреблению в нем эквивалента модального глагола to be to (are to pay) - «обязан по договору». С одной стороны, это иллокутивный акт «утверждения», а с другой, на него накладывается косвенный речевой акт, содержащий конвенциональную импликатуру «угрозы».

В русском переводе отсутствует смысловой оттенок «случайности - Случись, что не будет...», поэтому высказывание звучит более лаконично, реалистично, категорично и убедительно благодаря употреблению сказуемого в настоящем времени действительного залога, изъявительному наклоне- 
нию, наименованию исполнителя контракта в единственном числе «Продавец», что является особенностью делового стиля контрактов, заключаемых на русском языке. Имеет также место некоторое несоответствие информационных структур в исходном и переводящем языках. Дистантно расположенная рематическая предикатная группа, собственно отрицание, в английском придаточном предложении, представляющем контрастную макротему высказываний, соответствует в переводе препозитивной, контрастной, тематической группе косвенного дополнения «за неизвещение или несвоевременное извещение», выражающей нежелательное условие, которое приобретает в большей степени смысловой оттенок «реалистичности». Главное предложение в английском высказывании и соответствующая ему в целом сказуемостная группа в русском предложении выступают в рематической функции. Условно-следственные отношения исходного и переведенного высказываний и их коммуникативно-информационная структура в основном сохраняются.

5. Порядок следования главного и придаточного предложений, а также компонентов коммуникативно-информационной структуры высказываний в исходном и переводящем языках могут не совпадать в силу их культурно-языковых особенностей. Так постпозитивное придаточное условия в английском языке довольно часто переводится на русский либо препозитивным придаточным условия, либо лексико-грамматической группой, занимающей в высказывании начальное положение.

The period of guarantee of the normal and trouble-free operation of the equipment is to be 12 months from the date of putting it into operation...

The above period will be accordingly extended if start-up of the equipment is deferred or the operation of the equipment is stopped. - Сроки гарантии нормальной и бесперебойной работы оборудования 12 месяцев с даты пуска оборудования в эксплуатацию... В случае задержки в пуске в эксплуатацию оборудования или остановки оборудования в течение гарантийного периода названные сроки соответственно продлеваются. [8]

Первое изменение в переводе - это несоответствие абзацев: английское сложноподчиненное предложение с придаточным условия, выделенное в отдельный абзац, приобретает больший акцент. Следующие виды трансформации заключаются в сворачивании субъектно-предикатной структуры английского постпозитивного придаточного условия, выступающего в функции контрастного рематического компонента, до выделенной номинативной группы, выражающей нежелательное условие, занимающей начальное положение в высказывании и выступающей в функции контрастной темы. Содержание английского тематического главного предложения, непосредственно вытекает из предтекста благодаря анафорическому смысловому компоненту, подлежащему The above period, и косвенно - благодаря контрастной предикативной группе в рематической функции. В русском высказывании подлежащно-сказуемостная группа, соответствующая препозитивному тематическому главному предложению исходного английского, занимает постпозитивное положение и выступает в рематической функции. Так, в английском высказывании (в английском деловом сознании) наиболее значимым оказывается реализация условия, а в русском - следствие реализации этого условия.

6. Возможны более сложные и комплексные лексико-синтаксические преобразования: изменение синтаксической структуры, замена одних частей речи другими, некоторые изменения актуального членения в самих частях сложного высказывания при сохранении общей коммуникативноинформационной структуры всего высказывания, изменение функции членов предложения, опущение компонентов, представляющих прагматическую пресуппозицию; сворачивание синтаксической структуры, ведущее к компрессии информации.

We understand it is only by strictly observing the obligations that the sides will be able to complete the project in time and we would ask you to consider the letter carefully and take the required action.

Понимая, что только строгое выполнение обязательств обеими сторонами позволит успешно закончить строительство объекта вовремя, просим Вас внимательно изучить это письмо и принять необходимые меры [7].

При переводе данного сложносочиненного предложения-высказывания, состоящего из сложноподчиненного предложения с придаточным дополнительным в первой части, которое в свою очередь является сложноподчиненным предложением с придаточным подлежащим, и простого распространенного предложения во второй, применены разные переводческие трансформации, упомянутые выше: синтаксическая замена главного предложения we understand деепричастием понимая, вежливой формы выражения просьбы в сослагательном наклонении (the Subjunctive Mood) we would ask - Mbl попросили бы Вас глаголом в первом лице, множественном числе, изъявительном наклонении про- 
сим, которое стало сказуемым всего русского предложения; лексико-грамматические замены эмфатической герундиальной группы only by strictly observing в функции обстоятельства образа действия группой отглагольного существительного только строгое выполнение в функции подлежащего в придаточном дополнительном, замена подлежащего the sides в придаточном подлежащем номинативно-местоименной группой обеими сторонами в творительном падеже, эквивалента модального глагола в будущем времени «will be able to complete» (cможет закончить) - группой сказуемого с иной модальностью - «позволит успешно закончить», сообщающей смысловой оттенок каузации. В результате этих преобразований произошла синтаксическая замена сложносочиненного предложения со сложноподчиненным предложением с придаточным дополнительным, являющегося, по сути, придаточным подлежащим, простым распространенным предложением. В переводе сохранена когнитивная предметно-логическая информация, имплицитно присутствующие причинно-следственные отношения, общая коммуникативно-информационная структура высказывания. Опущение прагматической пресуппозиции: личного местоимения we - $\mathrm{mbl}$, этикетных фраз, упомянутых выше, привело к изменению некоторых прагмо-стилистических и модальных характеристик исходного высказывания. Высказывание в русском языке лаконично, более категорично, экспрессивно, выражая в большей степени настоятельную просьбу и даже требования; тематические компоненты: деепричастие понимая, подлежащная группа в придаточном дополнительном, а также рематическая сказуемостная группа позволит успешно приобретают большую степень контрастивности.

7. Сложноподчиненное предложение может быть переведено сложносочиненным, части которого соотносятся с придаточным и главным предложением исходного языка при сохранении порядка их следования, но изменением смысловых акцентов.

We have carefully studied your letter in which you write that you are concerned about possible delay in our commissioning the project.

Although we fully share your concern we would like to stress again that we are making every effort to meet the contract dates for all civil and erection works. -

Мы внимательно рассмотрели Ваше письмо, в котором Вы сообщаете, что обеспокоены вероятностью несоблюдения нами контрактных сроков сдачи объекта в эксплуатацию. -

Мы полностью разделяем Ваше беспокойство, однако хотели бы еще раз подчеркнуть, что мы принимаем все меры для завершения строительно-монтажных работ в предусмотренные контрактом сроки [7]

Всё сложноподчиненное предложение с придаточным уступительным в препозиции и главным предложением, представляющим сложноподчиненное предложение с придаточным дополнительным, переведено сложносочиненным предложением, части которого соединены противительным союзом однако и представляют собой ассепцию.

По своему содержанию первое простое предложение так же, как и придаточное, является уступкой. Опущение уступительного союза «although - хотя» облекает его в форму ассепции, благодаря чему более четко, категорично и убедительно выражается отношение адресанта-исполнителя к своему заказчику, характеризующееся сочувствием в возможной непростой ситуации.

Союз «однако», заменяющий союз «although - хотя» вводит вторую часть сложносочиненного предложения и актуализирует значение «противительности». Это позволяет адресанту более экспрессивно выразить «заверения» в принятии необходимых мер для выполнения заказа в сложившейся ситуации, успокоить заказчика и тем самым защитить себя от его возможных обвинений, на что указывает предтекст. Ассептивный характер частей сложносочиненного предложения в русском переводе придает больший динамизм, убедительность, характер «заявления» содержащимся в нем сообщениям и всему сложному высказыванию, а также более четко обозначает коммуникативные намерения адресанта-исполнителя.

Анализ переводов деловой коммерческой корреспонденции с английского языка на русский, показал, что во многих случаях при переводе сложных предложений-высказываний необходимо применение разнообразных переводческих трансформаций, требуемых для достижения адекватного перевода. При этом в ряде случаев может иметь место потеря и изменение информации этического, характера, но при обязательном сохранении передаваемой когнитивно-оценочной и важной прагматической информации, общей коммуникативно-информационной структуры высказывания. При соблюдении общих стилистических норм исходного и переводящего языков, характерных для письменного делового общения, наблюдаются и различия между ними, проявляющееся в большей лако- 
ничности, категоричности, реалистичности, напористости русскоязычных высказываний. Произведенные трансформации позволяют эксплицировать «эмоциональные психологические нюансы», придающие большую убедительность оценке ситуации и подчеркивающие понимание адресантом (одним из партнеров) значимости того или иного факта.

\section{СПИСОК ИСТОЧНИКОВ И ЛИТЕРАТУРЫ}

1. Бархударов Л.С. Язык и перевод. Вопросы общей и частной теории перевода. М.: Международные отношения, 1975. С. 191-232.

2. Веселов П.В. Аксиомы делового письма: культура делового общения и официальной переписки. Изд. 4-е, перераб. М.: ИВЦ «Маркетинг», 1993.

3. Игнатьева Т.С., Мясникова И.А. О трудностях перевода медицинского текста // Сб. материалов Междунар. научно-практ. конф. «Лингвистика. Лингводидактика. Переводоведение. Актуальные вопросы и перспективы исследования», Чебоксары, 20 ноября 2014 г. Вып. 1. С. 208-213.

4. Комиссаров В.Н. Современное переводоведение. Учебное пособие. М.: «ЭТС», 2004. С. 120-134, 147-148.

5. Комиссаров В.Н. Слово о переводе. Очерк лингвистического учения о переводе. М.: Международ отношения, 1973. С. 76-157.

6. Митрофанова 3.И. Пресуппозиции и их перевод // Сб. материалов Междунар. научно-практ. конф. «Лингвистика. Лингводидактика. Переводоведение. Актуальные вопросы и перспективы исследования», Чебоксары, 20 ноября 2014 г. Вып. 1. С. 223-228.

7. Памухина Л.Г., Любимцева С.Н., Дворникова Т.В., Жолтая Л.Р. Русско-английский разговорник по внешнеэкономическим связям. М.: Русский язык, 1992.

8. Шалыпина С.С. Чтение и составление контрактов на английском языке. М.: Изд. «Р.S.», 1991. С. 22.

Поступила в редакцию 14.06.2020

Михайлова Эльвира Рифкатьевна, кандидат философских наук, доцент кафедры иностранных языков № 2 ФГБОУ ВО «Чувашский государственный университет имени И.Н.Ульянова»

428015, Россия, г. Чебоксары, пр-т Московский, 15

E-mail: elvira.mikhailova@yandex.ru

\section{E.R. Mikhailova \\ SOME PECULIARITIES OF TRANSLATION OF COMPOSITE SENTENCES (ON THE MATERIAL OF BUSINESS COMMERCIAL CORRESPONDENCE IN ENGLISH AND IN RUSSIAN)}

DOI: $10.35634 / 2412-9534-2021-31-2-264-270$

The present article considers some of the peculiarities of translation of complex and compound sentences used in business correspondence in English and in Russian. Translation of these utterances demands taking into account all the variety of information expressed by them as well as their pragmatic and stylistic peculiarities. Different translation transformations are used to perform adequate translation, such as: rearrangements, replacements, additions, omissions. In some cases, there may be loss and change of ethical information, but with mandatory preservation of the transmitted cognitive-evaluative and important pragmatic information, the general communicative-informational structure of the statement. Subject to the general stylistic norms of the source and translating languages that are characteristic of written business communication, differences are also observed between them, manifested in greater conciseness, categoricalness, realism, and assertiveness of the statements in Russian. The transformations made allow us to explicate "emotional psychological nuances" that give greater credibility to the assessment of the situation and emphasize the understanding by the addressee (one of the partners) of the significance of one or another fact.

Keywords: utterances presented by complex and compound sentences, translation transformations, adequate translation, levels of equivalence, communicative structure of an utterance.

\section{REFERENCES}

1. Barkhudarov L.S. Yazyk i perevod. Voprosy obshchey i chastnoy teorii perevoda [Language and translation. Questions of general and particular theory of translation]. M.: Mezhdunarodnyye otnosheniya [International Relations], 1975, pp. 191-232. (In Russian). 
2. Veselov P.V. Aksiomy delovogo pis'ma: kul'tura delovogo obshcheniya i ofitsial'noy perepiski [The axioms of business writing: a culture of business communication and official correspondence]. M.: IVTS «Marketing», 1993. Izd. 4-ye, pererab. (In Russian).

3. Ignat'yeva T.S., Myasnikova I.A. // Sb. materialov Mezhdunar. nauchno-prakt. konf. «Lingvistika. Lingvodidaktika. Perevodovedeniye. Aktual'nyye voprosy i perspektivy issledovaniya» [Materials of the Intern. scientific and practical. conf. "Linguistics. Linguodidactics. Translation Studies. Actual questions and research prospects], Cheboksary, 20 November, 2014. Ed. 1. P. 211.

4. Komissarov V.N. Sovremennoye perevodovedeniye. Uchebnoye posobiye [Modern translation studies. Tutorial]. M.: «ETS», 2004. Pp. 120-134, 147-148.

5. Komissarov V.N. Slovo o perevode. Ocherk lingvisticheskogo ucheniya o perevode [A word about translation. Essay on the linguistic doctrine of translation]. M.: Mezhdunarod otnosheniya [International Relations], 1973. Pp. 76-157.

6. Mitrofanova Z.I. // Sb. materialov Mezhdunar. nauchno-prakt. konf. «Lingvistika. Lingvodidaktika. Perevodovedeniye. Aktual'nyye voprosy i perspektivy issledovaniya» [Materials of the Intern. scientific and practical. conf. "Linguistics. Linguodidactics. Translation Studies. Actual questions and research prospects], Cheboksary, 20 November, 2014. Ed. 1. P. 223.

7. Pamukhina L.G., Lyubimtseva S.N., Dvornikova T.V., Zholtaya L.R. Russko-angliyskiy razgovornik po vneshneekonomicheskim svyazyam [Russian-English phrasebook on foreign economic relations]. M.: Russkiy yazyk [Russian language], 1992.

8. Shalypina S.S. Chteniye i sostavleniye kontraktov na angliyskom yazyke [Reading and drafting contracts in English]. M.: Izd. «P.S.», 1991.

Received 14.06.2020

Mikhailova E.R., Candidate of Philosophy, Associate Professor, Department of Foreign Languages № 2

Chuvash State University

Moskovskii prospect, 15, Cheboksary, Russia, 428015

E-mail: elvira.mikhailova@yandex.ru 